\title{
Exploration and Research About folk Sports in China
}

\author{
Chunjie Zhao \\ College of Physical Education, Hebei Normal University, Shijiazhuang, 050024, China
}

Keywords: Traditional ethnic sports, Folk custom sports, Exploration

\begin{abstract}
The folk sports is the cross product of folklore and sports science, by building the folk sports learning has a positive impact on the development of disciplines, and to strengthen people's spiritual civilization and material civilization construction has important practical significance. To strengthen the research of folk sports learning can fully exert sports activities contained in the spirit of folk custom. This article from our country folk sports science research status, research the value of the folk sports in many ways, such as analysis, and the development of folk sports in our country for the future study and concrete Suggestions were put forward.
\end{abstract}

\section{Introduction}

Folk sports is an important part of our traditional national culture, to our country's construction of socialist spiritual civilization and material civilization has played a positive role, especially to promote the development of regional culture has played a good effect. But, at present, the development of the folk sports, it due to the impact of western sports culture, the development of folk sports there are greater difficulties, and even in some areas appear crisis of folk sports gradually disappear. Therefore, related education department and cultural department should pay more attention to folk sports heritage and construction work. Through the study of the exploration and research of folk sports, folk sports of various areas in order to build up the unique folk sports system in our country, and in the construction of regional culture, give full play to the role of the folk sports, strengthen the construction of spiritual civilization and material civilization.

\section{Restriction factors of our country's folk sports}

In the process of the current development of folk sports is resistance from all sides with obstacles, mainly includes the following aspects:

\section{Lack of correct positioning of society and publicity}

Folk sports is in the process of the ethnic culture development of our country develops gradually, so carrying the rich ethnic culture in the folk sports, folk sports development need the whole people to participate in an, but, at present, the development of the folk sports, folk sports lack correct social position, people cannot realize the importance of the development of folk sports, also cannot timely propaganda and promotion.

\section{It has not built perfect development theory system yet}

Along with our country strengthen the protection of non-material culture, and declare at the United Nations educational, scientific and cultural organization after the non-material heritage, people's consciousness of national culture to the effective promotion, but has not formed the system of theoretical system, so for the development of folk sports also failed to build up the guidance of the scientific theory system, the development of folk sports is lack of scientific guidance.

\section{Blind pursuit of western sports culture}

With the economic globalization, more and more western culture thought into the domestic, the western sports thought also has important influence on the development of sports in China, people blind pursuit of western sports, makes the country's folk sports development limited, and the diversity and richness of folk sports also fade away.

\section{Excessive pursuit of economic value, ignore cultural construction}

Some areas can be found in the folk sports because of the economic value, in the economic development of the economic value of folk sports full development, especially in the development of 
tourism industry, the form of folk sports and sports for development and development as regional tourism characteristics. However, in the process of its development and pay more attention to the development of its economic value, ignores its cultural value contains, long term will destroy the excellent culture connotation, folk sports itself which affects the healthy development of folk sports $^{[1]}$.

\section{The necessity of research on folk sports learning}

\section{Build perfect folk sports system}

Each region of the different folk sports activities can fully reflect the construction of spiritual culture and the local traditional customs. In Hulunbeir, in Inner Mongolia autonomous region, for example, with a large number of local Mongolian nomads, due to the generations to come live in the prairie, so the local retained the traditional sports, horse racing and wrestling. People in the end the day after grazing will together for horse racing and wrestling. And suffer in the Inner Mongolia autonomous region in Nardam festival held in July and August of each year, because this season the prairie grasses fair, Livestock disease, the weather is cool, the athletes from different regions meet competition, make the traditional customs of the Mongolian in the brave, witty and courageous, good moral character can down from generation to generation. Inner Mongolia folk sports activities both inherited the excellent moral character of the culture of the Chinese nation, also keeps a good part in the development of the local culture. Geographical area of our country is vast, and there are many minority ethnic groups, through strengthening the folk sports studies can be summarized the folk sports activities of various areas and excavation, this can be effective rich folk sports theoretical system in our country ${ }^{[2]}$

\section{To strengthen our country's folk culture heritage and development}

Throughout the development of sports in China, influenced by the western sports culture and the impact, folk sports development is facing great crisis. And in recent years, with the accelerating urbanization construction in our country, some folk sports activities in the city cannot conduct will gradually disappear, making the traditional customs and culture of sports activities is also dissipated. Therefore, in order to strengthen protection and construction of the traditional culture of our country, in the national "11th five-year plan" period cultural development plan outline there are specific rules, to make our country's customs and all kinds of festival can conform to the development of modern society, and the construction of spiritual civilization and peace. The development of folk sports and to strengthen the construction of spiritual civilization, and in the process of its development innovation, make the folk sports in the form of a more diverse, more rich content, combined with the time development of some of the customs and festivals for improvement and innovation, but to keep the core value of customs. In 2011 and issued and implemented the "intangible cultural heritage of the People's Republic of China law, the emphasis on the excellent cultural tradition, the protection and inheritance of the Chinese nation, folk sports as an important part of national culture is also protected. Folk sports carrying the rich national spirit and national culture, so the research on folk sports, folk sports can not only be exploration and discovery, also it can promote to our country outstanding traditional culture inheritance and development ${ }^{[3]}$.

To promote the region economic development and cultural construction is conducive to promoting regional social and economic development

Modern economic development of sports economy occupies a very important position, and gradually into a system of industrial sectors, the sports of the whole social construction of spiritual culture construction and economic development, which play an important role. But as far as the present situation of development of folk sports, has not aroused people's wide attention, folk sports should not be included in the excavated cultural construction value and economic value. If you can use the local characteristics of folk sports and customs and the local tourism resources, the folk sports as part of the tourism resources, it can give full play to its economic functions, create greater economic value. Effectively improve the economic level and quality of life of the local people. And through the study of local folk sports, which can undertake combing on the local culture, local culture can be mining and then found that unearthed for the cultural essence of the modern spiritual culture 
construction, strengthen the construction of spiritual culture, thus effectively improve the local social cohesion, for effective social control and management, and promote regional harmonious development.

\section{Countermeasures for the development of folk sports in China}

\section{Countermeasures for the development of folk sports in China, adhere to sustainable development}

The concept of scientific development and sustainable development is the concept of our country to strengthen the construction of the social attention to absorbing, guiding the socialist economic and cultural development of important thought. Therefore, the development of folk sports also wants to see this as a guiding ideology, and actively explore the education development of the folk custom body model. In a sustainable development view as the guiding ideology of the folk sports development, should pay attention to in its development model to explore the following questions: first, should establish people-oriented concept of value, which is the basic goal of strengthening the construction of folk sports, also is the fundamental starting point of the inheritance of folk sports, second, to promote the local folk sports development is also an important means of promoting local spiritual construction and economic construction, so attention should be paid to combine all the factors, and allow it to each other coordinated development; Finally, but also promote each other between each local folk sports coordination and development, and make the development of folk sports closely combined with the construction of spiritual culture, some do not tally with the time development of sports for improvement and innovation, slam the door behind some sports, make the development of folk sports can keep with the time development ${ }^{[4]}$.

\section{Combined development of folk sports and school sports education}

Combine folk sports and school sports teaching, on the one hand can meet the needs of the folk sports development and the inheritance, on the other hand also can effectively expand the content of the school sports education, thus it will be introduced to the folk sports in school sports education. At the same time, as a result of the school sports teaching in administrative class as the unit, can concentrate on teaching, student is the main part of the future society talents, teach students the folk sports can make it a better inheritance and development. Therefore, you can fully explore the combination of school sports teaching and folk sports mode, the school as an important platform of heritage and development of folk sports. But in the actual teaching should pay attention to the following questions: first, the need to be approved by the relevant government departments, and to solicit the opinions of the masses of teachers and students; Second, it needs to organize the professional team of experts and scholars, the study of local folk sports items, because some sports have a certain risk is not easy in the school organization to carry out teaching activities, such as archery, wrestling and other more intense project, the selection folk sports should fully consider the student's physical body when conditions, choose can promote the development of adolescent physical and mental health of folk sports teaching; Again, after the selection of sports, and organize the relevant experts of folk sports teaching material writing, it makes it more standardized, which can also according to the social development of the sports in some details of the improvement and innovation; Finally, after completion of the folk sports project selection and compiling textbooks, pilot experiments in a few schools, to the specific teaching methods, teaching effect is summarized, such as improving the part of the problem, and to promote in the whole region. So you can use the platform of the school sports teaching will develop folk sports heritage, enriched the connotation of the folk sports more ${ }^{[5]}$.

\section{Explore the folk sports' economic potential}

With the development of the market economy and change, the sports market must also go change and reform; it is also a folk sports development path and the inevitable result. Therefore, in the process of the development of folk sports should continuously explore the development of the market characteristics and development pattern, fully tap it contains economic resources, to create a higher economic value. To excavate the economic potential of folk sports included in the need to do the following: first, the local government to give certain policy inclination and economic support, to 
support the development of folk sports organizations, enterprises, both in its business, tax and land to take positive measures to support; Second, the government will also fitness of sports market, enterprise, integrating tourism resources of enterprise, and its culture as the main force of the development of folk sports, and gradually to attract some folk idle capital to invest in the development of sports industry; Finally, in the sports market in the process of development must be combined with the local actual situation, and the development of sports market economy with local characteristics, it forms a core competitiveness of sports products, developing the sports brand.

\section{Set up the development of folk sports brand awareness}

Form a brand is a result of the development of regional cultural construction and spiritual civilization, is the local economy culture and science and technology the important symbol of comprehensive development, also can fully reflect the people's standard of living. So it is necessary to set up the folk sports brand, in the development of folk sports from around to through continuous accumulation, is entirely possible in the creation of local folk sports brand. In order to develop folk sports brand, first of all, to establish brand awareness in the process of sports development around the, can let the local people realize the importance of forming folk sports brand, can form a national building and public participation, social atmosphere of folk sports brand shaping. Second, to compare the local representative of folk sports activities as a key object in the brand development and training, government should give organizations, funds, talents, and promotion of investment, expand the influence of the folk sports activities, and improve the brand influence and popularity. Finally, be suitable for the local folk sports development strategy, the formation of brand strategy, brand of government for the folk sports activities of scientific and reasonable planning for a long time, for the folk sports brand positioning, character design and so on carries on the careful discussion and planning.

\section{Conclusion}

Folk sports is an important part of our traditional national culture, to our country's economic development and the construction of spiritual culture made outstanding contributions, especially for the regional economic development play a positive role in promoting. Under the impact of the modern western sports culture, the development of folk sports facing a huge crisis, and even some sinking into the predicament of the development of the project. But the folk sports in carrying our excellent national culture tradition, once the folk sports disappear, also will lose a good culture, therefore, must want to explore and research on the development of folk sports learning, fully tap its contains the economic value and social function, strengthen the construction of folk sports, to inherit and inheritance of national culture and drive the healthy development of regional economy.

\section{References}

[1] Li Peng. The mass media to influence the folk sports development survey analysis of TianJin, Shandong, Xinjiang,Hubei, Henan. Journal of Nanjing institute of sport (social science edition), 2012,(5).

[2] Chuojing, Wang Ruoguang, Liu Minhang. The history and present situation of our country folk sports. Journal of sports science research.2010(1)

[3] Xiang Jun, Guo Huijie, Liu Xiaoming, Fang Qianhua. The commentary of researching progress of Chinese folk sports (1997-2014). Journal of sports science research,2015(4)

[4] Duan Jinshi, Yin Naiying, Liu Zhenjun. Under the background of the construction of new countryside folk sports and the linkage of the national fitness project development research - in Shanxi Province, for example. Journal of Jilin institute of sport,2013(2)

[5] Li Gang, Liang Junxiong, Liu Li, Wenbo. The research about the folk sports in west of Guangdong province university sports school-based curriculum development. Journal of sport science and technology literature,2014(12) 